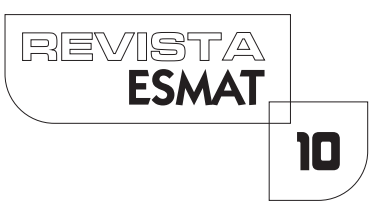

\title{
REORDENAÇÃO DO TERRITÓRIO E GOVERNANÇA SOCIOAMBIENTAL: OS MOSAICOS DE ÁREAS PROTEGIDAS NO BIOMA AMAZÔNIA
}

REORGANIZATION OF THE TERRITORY AND SOCIALENVIRONMENTAL GOVERNANCE: THE MOSAICS OF AREAS PROTECTED AREAS IN THE AMAZON BIOMA

Marco Anthony Steveson Villas Boas

Desembargador com Assento no Tribunal de Justiça do Tocantins, Diretor Geral da Escola Superior da Magistratura Tocantinense (ESMAT) e Vice-Presidente do Colégio Permanente de Diretores das Escolas Estaduais da Magistratura (COPEDEM), Vice-Presidente, Corregedor e Diretor da Escola Judiciária Eleitoral (EJETO) do Tribunal Regional Eleitoral (TRE) do Tocantins; exPresidente do Tribunal de Justiça do Tocantins, do Colégio de Presidentes de Tribunais Eleitorais do Brasil (COPTREL) e do Colégio de Corregedores Eleitorais do Brasil (COCEL). Mestre em Direito Constitucional pela Faculdade de Direito da Universidade de Lisboa (FDUL). E-mail: marcovillasboas@uol.com.br.

\section{RESUMO}

A Constituição de 1988 estabeleceu um eixo transversal de proteção do ambiente, perpassando, principalmente, os subsistemas da economia, da educação e cultura, dos índios e das populações tradicionais, sustentado por um verdadeiro princípio socioambiental, o qual tem influenciado a legislação, a jurisprudência e proporcionado a inclusão de terras indígenas, terras quilombolas e de outras populações tradicionais dentro do Sistema Nacional de Unidades de Conservação (SNUC), instituído pela Lei n. 9.985, de 2000, inclusive em Mosaicos de gestão compartilhada. Essa vertente socioambiental tem dado concreção ao princípio democrático e permitido a inclusão social, uma vez que se admite a formação de Mosaicos de áreas protegidas, compostos por Terras Indígenas e de populações tradicionais, Unidades de Conservação, Zonas de Amortecimento e Corredores Ecológicos, e possibilita a participação dos indígenas e populações tradicionais na gestão do sistema.

PALAVRAS-CHAVE: Corredores ecológicos; Democracia; Meio ambiente; Mosaicos; Socioambientalismo. 


\begin{abstract}
The 1988 Constitution has established a transversal axis of environment protection, wich includes the subsystems of economy, education and culture, from indigenous people and traditional populations, supported by a true socioenvironmental principle, which has influenced legislation, jurisprudence and provided the inclusion of indigenous lands, quilombola lands and other traditional populations within the National System of Conservation Units (SNUC), established by Law no. 9.985, of 2000, including in mosaics of shared management. This socioenvironmental aspect have given concrete expression to the democratic principle and allowed social inclusion, since it allows the formation of mosaics of protected areas, composed of indigenous lands and traditional populations, conservation units, cushion zones and ecological corridors, which allows the participation of indigenous and traditional populations in the management of the system.
\end{abstract}

KEYWORDS: Ecological corridors; Democracy; Environment; Mosaics; Socioenvironmentalism.

\title{
INTRODUÇÃO
}

A constitucionalização da proteção do ambiente, inspirada na Constituição da República Portuguesa, e ao mesmo tempo marcada pelo rico historicismo multicultural e pluriétnico, característico da formação do povo brasileiro, fez resplandecer o princípio socioambientalista na Constituição de 1988, no qual gravita um eixo alinhado transversalmente que perpassa os principais subsistemas, notadamente os dedicados ao meio ambiente, economia, educação e cultura (populações tradicionais) e índios.

Essa juridicidade plasmada na Constituição de 1988, em decorrência dos fatores reais de poder que convergiram nesse sentido durante os trabalhos da Assembleia Nacional Constituinte, influenciou as Cimeiras do Rio de Janeiro em 1992 e 2012, e proporcionou avanços na legislação infraconstitucional, nas políticas públicas de proteção ao ambiente e nas decisões judiciais, notadamente nas do Supremo Tribunal Federal, o qual tem garantido, contramajoritariamente, direitos de minorias, promovendo a concreção material do princípio democrático.

Sob esses influxos, a vertente ecocêntrica de proteção das unidades de conservação no Brasil, ainda que explicitamente adotada pela Lei n. 9.985, de 2000, (Lei do SNUC), cedeu a esse forte componente socioambiental e incluiu no seu sistema unidades de conservação de uso sustentável, em que se admitem determinados níveis antrópicos e o extrativismo submetido a manejo adequado. 
Nesse compasso, o Plano Estratégico Nacional de Áreas Protegidas (PNAP), instituído pelo Decreto n. 5.758, de 2006, cuidou de estabelecer um elo entre o SNUC e o Estatuto do Índio (Lei n. 6.00 I, de 1973) e reconhecer a transcendência ambiental das terras indígenas, na condição de áreas protegidas, vertente reiterada pelo Decreto n. 7.747, de 2012 (PNGATI), que institui um programa nacional voltado à preservação ambiental de terras indígenas.

O problema que emerge dessa regulamentação consiste em antinomias e políticas públicas deficitárias, as quais acabam ocasionando falta de eficácia normativa, principalmente dos Decretos n. 5.758, de 2006, e 7.747, de 2012.

Nesse contexto, examinam-se algumas hipóteses: a) partindo-se do pressuposto de que as terras indígenas possuem valor ambiental, segundo dispõe o art. 23l da Constituição Federal, seria juridicamente possível a composição de Mosaicos entre Unidades de Conservação de máxima proteção, Unidades de Conservação de Uso Sustentável e Terras Indígenas?; b) é possível a inclusão de indígenas e de integrantes de populações tradicionais no sistema de gestão e conservação dessa espécie de Mosaico, remunerando-os pela prestação de serviço ambiental?; c) seriam benéficas ao Sistema Nacional de Unidades de Conservação a composição e a interligação de Mosaicos, por meio de reordenamento do território, em regime de cooperação entre a União, Estados e Municípios, com participação da sociedade civil, indígenas e populações tradicionais?

O objetivo dessa abordagem é o de trazer à reflexão o futuro das áreas protegidas na Amazônia Legal, difundir o sistema de Mosaicos e instigar a inserção das comunidades indígenas e tradicionais na gestão dessas áreas, com remuneração por prestação de serviços ambientais, estabelecendo-se um sistema de governança socioambiental.

Busca-se resolver o problema delimitado, por meio do método qualitativo e do dedutivo, valendo-se de pesquisa na legislação, doutrina e jurisprudência.

No item I, aborda-se o Sistema Nacional de Unidades de Conservação (SNUC) e suas vertentes ecocentristas e socioambientalistas. $\bigcirc$ relacionamento dos indígenas e das populações tradicionais com o sistema é tratado na seção 2; no item 3, cuida-se de demonstrar o valor ambiental das terras indígenas e das terras ocupadas por outras populações tradicionais, assim como a evolução jurídica dessa proteção. No item 4, abordam-se a definição jurídica e a composição dos Mosaicos, enquanto a gestão, pagamento por serviços ambientais e outras peculiaridades do sistema são tratadas no item 5. Por derradeiro, o ordenamento do território é trazido a lume no item 6, em um contexto socioambiental, como instrumento para alavancar ordeiramente o desenvolvimento dentro de critérios de sustentabilidade.

\section{O SISTEMANACIONALDE UNIDADES DE CONSERVAÇÃO}

A ideia ecocêntrica baseada na concepção mítica de uma natureza intocada e estática, que afasta a presença humana do ambiente natural, inspirou a proteção 
ambiental na Europa e nos Estados Unidos no último século, e influenciou o modelo adotado inicialmente no Brasil (DIEGUES, 200 I , p. 9- I0), a partir da criação de grandes parques ambientais, mas que acabou se abrindo para o antropocentrismo (ARAÚJO, 2012, p. 48) sedimentado no curso da formação pluriétnica e multicultural do povo brasileiro, mais particularmente pela participação do elemento índio em nossa sociedade (VILLAS BOAS, 20 I 3b, p. 68).

A Convenção da Diversidade Biológica (art. 8 , "j"), a Declaração das Nações Unidas sobre os Direitos dos Povos Indígenas (Res. 6I/295) e o Anexo I, n. 49, da Assembleia Geral das Nações Unidas (Res. 66/288) sacramentaram o modelo antropocêntrico alargado de proteção ambiental adotado pelo Brasil, o qual também é defendido por Guido Soares, principalmente em relação aos índios, os quais, segundo ele, são naturais protetores da fauna e da flora, e devem ser incluídos preferencialmente nas políticas públicas e ações governamentais para conservação do meio ambiente. (SOARES, 200 I , p. 82).

Malgrado o Sistema Nacional de Unidades de Conservação (SNUC), instituído pela Lei n. 9.985, de 2000, não excluir a máxima proteção por parte do Estado sobre áreas que necessitam de baixo ou nenhum nível antrópico, trouxe as primeiras perspectivas de convivência das populações tradicionais com unidades de conservação e a possibilidade de composição de Mosaicos de Unidades de Conservação.

A técnica legislativa adotada pela Lei n. 9.985 é de um sistema de gradação da intensidade protetiva relacionada à presença humana, dividido em dois grupos: Unidades de Conservação de Proteção Integral e Unidades de Conservação de Uso Sustentável e Indireto. A diferença entre esses grupos consiste na forma de utilização dos recursos naturais neles existentes ou deles provenientes. Nas Unidades de Conservação de Proteção Integral, o uso dos recursos se dá de forma indireta, sem ações que envolvam coleta, consumo, dano ou destruição desses recursos. De outro modo, nas Unidades de Conservação de Uso Sustentável, é possível o uso moderado de seus recursos. As primeiras estão direcionadas a um baixo nível antrópico e subdividem-se em: Reserva Biológica (REBIO), Estação Ecológica (ESEC), Parque Nacional (PARNA), Monumento Natural (MONAT) e Refúgio de Vida Silvestre (RVS). As Unidades de Conservação de Uso Sustentável, como o próprio nome sugere, buscam compatibilizar o uso racional de parte dos recursos naturais com a preservação do ambiente natural e subdividem-se em: Áreas de Proteção Ambiental (APA), Floresta Nacional (FLONA), Reserva de Fauna (REFAU), Reserva Extrativista (RESEX), Reservas de Desenvolvimento Sustentável (RDS), Reserva Particular do Patrimônio Natural (RPPN), Áreas de Relevante Interesse Ecológico (ARIE). Além disso, existe a previsão de instituição de Zona de Amortecimento no entorno de Unidades de Conservação, com normas e restrições específicas de atividades antrópicas, com a finalidade de abrandar o impacto deletério. (BELTRÃO, 20 I I, p. 4- I0).

As Unidades de Conservação dependem de ato do Poder Legislativo (lei) ou Executivo (decreto ou portaria) para criação, sejam elas de proteção integral ou de uso 
sustentável, o que as diferenciam dos espaços especialmente protegidos.

Apesar de a Lei n. 9.985, de 2000, impor a realização de estudos técnicos e de consulta pública para a criação de unidade de conservação, as populações indígenas impactadas com a criação da UC, assim como em outras ações governamentais, não têm recebido a devida atenção nesse processo.

Tal situação ganha contornos mais relevantes, sob o ponto de vista de que o sistema instituído pela Lei n. 9.985, do SNUC, influenciado pelo pensamento conservacionista ecocêntrico, findou por estabelecer uma gradação que exclui até mesmo indígenas e populações tradicionais de certas unidades de conservação, tendência que vem se alterando nas políticas públicas no transcorrer dos últimos anos.

Todavia, no modelo de unidade destinada à conservação da biodiversidade ou extrativismo sustentado, são autorizadas atividades como o turismo, a educação ambiental e o extrativismo madeireiro e não madeireiro de manejo planejado e sustentável, além de permitida a presença de populações tradicionais desde que realizem atividades sob o regime de manejo.

A abertura para a presença de populações tradicionais em Unidades de Conservação é de suma importância para se dar concreção aos direitos dessas minorias e fortalecer a democracia, promovendo uma vertente socioambientalista de conservação ambiental. A realidade, advinda dos fatores reais de poder, tem contribuído para a evolução do sistema, segundo pontua Adalberto Veríssimo, anotando o considerável crescimento das unidades de conservação de uso sustentável, especialmente na Amazônia Legal (20 I I, p. 25).

Essa tendência proporcionou o alargamento do sistema e inclusão das Terras Indígenas no contexto das políticas públicas de proteção ambiental pelo Plano Estratégico Nacional de Áreas Protegidas (PNAP) e pelo Programa Nacional de Gestão Territorial e Ambiental de Terras Indígenas (PNGATI), instituídos pelos Decretos n. 5.758, de 2006, e 7.747, de 2012.

\section{UNIDADES DE CONSERVAÇÃO, POPULAÇÕES INDÍGENAS E TRADICIONAIS}

A proposta de criação de reservas extrativistas, como espécie de reforma agrária ambientalista, antecede a Lei do SNUC, e se adequava ao discurso multiculturalista em voga nas agências internacionais de cooperação nas décadas de 1980 e 1990, com a diferença de que a terra de domínio da União, tal qual a terra indígena, não poderia ser transferida a particulares, mas tão somente seu usufruto, por meio do sistema de concessão de direito real de uso aos seringueiros. (SANTILLI, 2005, p. 3940).

Era uma proposta diferenciada de exploração econômica, sensivelmente voltada para o tema ambiental, em que áreas de floresta de aproximadamente 300ha, cada uma, permaneceriam preservadas praticamente em sua integralidade, aos cuidados dos 
cessionários seringueiros, destinadas ao extrativismo do látex e ao plantio de hortas, algumas linhas de árvores frutíferas e pequenas áreas de roças para subsistência familiar.

Parece ser essa a primeira grande conquista de visibilidade perante a comunidade local e internacional, o entrelaçamento de políticas públicas voltadas à promoção da reforma agrária e preservação ambiental, marco temporal do socioambientalismo brasileiro.

A inclusão das comunidades locais nas políticas públicas ambientais com vistas a um desenvolvimento sustentável abriu perspectivas para distribuição de riquezas mais equitativas e justas, de forma a densificar o princípio da liberdade, na esteira do que defendem Amartya Sen (20 I I, p. 283) e Bonfil Batalla ( 1990, p. 230-23 I), numa linha etnodesenvolvimentista, que Boaventura de Sousa Santos (2012, p. 30) denomina ecossocialista, um novo paradigma de desenvolvimento multiculturalista e pluralista, que se contrapõe ao modelo capital-expansionista.

As primeiras reservas extrativistas, porém, somente foram criadas em 1990, proporcionando ascensão política do movimento sindical e ambiental dos seringueiros.

A previsão de unidades de conservação de uso sustentável trazida pela Lei do SNUC e a realidade vivida em diversas regiões, principalmente na Amazônia, com a consequente inversão da tendência, conforme anteriormente mencionado, colocam o sistema num panorama mais tendente ao socioambientalismo.

Nesse contexto, vêm perdendo força normativa os arts. 35 e seguintes do Decreto n. 4.340, de 2002, os quais tratam do reassentamento de populações tradicionais estabelecidas em Unidades de Conservação, assim como o uso desse paradigma na solução de sobreposições entre Terras Indígenas e Unidades de Conservação.

Conquanto a Lei n. 9.985, de 2000, tenha se referido a populações tradicionais, não incluiu os indígenas e suas áreas de terras no seu sistema de proteção, situação que alguns doutrinadores atribuem à proteção constitucional exclusiva e à legislação especial aos direitos indígenas e suas terras.

De outro modo, o Plano Estratégico Nacional de Áreas Protegidas (PNAP), instituído pelo Decreto n. 5.758, de 2006, cuidou de estabelecer um elo entre o SNUC e o Estatuto do Índio (Lei n. 6.00 I , de 1973) e reconhecer a transcendência ambiental das terras indígenas, na condição de áreas protegidas.

Essa vertente, como adiante se verá, foi melhor explicitada por meio do Decreto $n$. 7.747, de 5 de junho de 2012 (PNGATI), que institui um programa nacional voltado à preservação ambiental de terras indígenas. No entanto, essa proteção já se encontrava delineada no art. 231 da Constituição de 1988, que incluíra, numa concepção socioambiental, as áreas indígenas sob a proteção do Estado, ao qual cabe a tarefa constitucional de dar concreção a esse dispositivo pelo reconhecimento e demarcação das terras indígenas e da execução de políticas públicas necessárias à proteção e recuperação dessas áreas. (VILLAS BOAS, 201 3al , p. 3392).

Uma leitura atenta do dispositivo leva a uma irrefutável conclusão de que a linha adotada pelo legislador em matéria de proteção aos direitos indígenas é nitidamente 
socioambiental, e permite essa transversalidade com outros subsistemas, inclusive com o do meio ambiente, pois é atribuição da União, segundo o caput do mencionado art. 231 , velar pela proteção de todos os bens da terra indígena, donde se conclui que dentre eles, em primeiro plano, estão os bens naturais, as florestas, rios, lagos, animais, solo e subsolo, essenciais ao seu bem-estar(VILLAS BOAS, $2013 b$, p. 72).

Essa realidade, claramente explicitada nos Anais da Assembleia Nacional Constituinte, aliada às tendências das últimas convenções sobre meio ambiente realizadas pelas Nações Unidas, principalmente no que se refere à CDB e COPs, certamente influenciaram as políticas públicas conservacionistas, proporcionando que as terras indígenas fossem formalmente incluídas no sistema nacional pelo PNAP.

As populações tradicionais dependem diretamente dos recursos naturais para sobreviverem, motivo pelo qual são favoráveis à preservação, seja para assegurar sua sobrevivência ou mesmo para ressaltar sua legitimidade diante do Estado. (VILLAS BOAS, 20।3b, p. 50).

Destarte, apesar da predominância ecocêntrica no sistema protetivo da Lei n. 9.985, de 2000, seria possível jurídica e cientificamente a sobreposição de Terras Indígenas e Unidades de Conservação de Proteção Integral em diversas hipóteses, inclusive em relação ao Parque Ambiental e Monumento Natural, conforme foi decidido pelo Supremo Tribunal Federal (STF) no julgamento da demarcação da Terra Indígena Raposa Serra do Sol (Pet. 3.388/RR), vertente que auxiliará na composição de diversos conflitos socioambientais na Amazônia, decorrentes de sobreposições de áreas protegidas.

\section{PROTEÇÃO DAS TERRAS INDÍGENAS NO ÂMBITO DO PNAPE DA PNGATI}

O Plano Estratégico Nacional de Áreas Protegidas (PNAP), instituído pelo Decreto n. 5.758, de 13 de abril de 2006, veio para dar cumprimento aos compromissos assumidos pelo Brasil dentro do Programa de Trabalho sobre Áreas Protegidas da CDB, na COP-7 (Marrocos, 200 I); e reiterado na COP-8 (Curitiba, 2006).

A grande novidade do Decreto n. 5.758, de 2006, foi o expresso reconhecimento do valor ambiental das terras indígenas pelos órgãos governamentais, que até então estava adstrito às convenções da $\mathrm{ONU}$, tendo em vista a já mencionada exclusão dessas áreas protegidas do SNUC (Lei n. 9.985, de 2000).

O PL 2.057, de 1991, de autoria do deputado Aloízio Mercadante, já trazia em seu texto original, com maior clareza, o valor ambiental das terras indígenas, ainda que não Ihe desse efetivo status de unidade de conservação. Entretanto, a paralisação desse projeto tem exigido novas interpretações do atual Estatuto do Índio à luz da Constituição de 1988, com as necessárias adaptações para garantir políticas públicas condizentes com as necessidades dos povos indígenas.

Conquanto o artigo 34 do Estatuto do Índio e o artigo $1^{\circ}$ da Lei que instituiu a Funai (Lei n. 5.37I, de 1967) conferissem indiretamente à Fundação Nacional do Índio 
atribuição de velar pelo equilíbrio ambiental das terras indígenas, dentro de uma interpretação conforme o texto do art. 225 da Constituição, o expresso reconhecimento desse valor ambiental veio somente com a instituição do PNAP, cujo objetivo expresso preambularmente no Decreto 5.758, de 2006, é o de estabelecer um plano integrado de gestão "de áreas protegidas, ecologicamente representativo e efetivamente manejado, integrado a paisagens terrestres e marinhas mais amplas até 2015."

Na esteira do PNAP, o Ministério do Meio Ambiente publicou a Portaria n. 63, de 12 de junho de 2006, que criou a Comissão Coordenadora do Plano Estratégico Nacional de Áreas Protegidas para funcionar como instância colegiada consultiva, com a finalidade de orientar, acompanhar e apoiar a implementação do plano. A eclética Comissão congrega atores governamentais e não governamentais, inclusive da Funai, além de membros da sociedade em geral, da iniciativa privada, mas principalmente índios e quilombolas, conforme se depreende do seu art. $2^{\circ}$, criando o ambiente propício para a implantação de tão esperada governança ambiental.

Ao lado disso, o Decreto n. 7.747, de 20 I2, instituiu a Política Nacional de Gestão Territorial e Ambiental de Terras Indígenas (PNGATI), que veio para dar mais sentido e direção ao Decreto n. 5.758, de 2006, e revascularizar o socioambientalismo brasileiro, abrindo novas perspectivas para que as terras indígenas sejam efetivamente reconhecidas pelo Governo e pela sociedade como verdadeiras reservas ambientais, de vital importância para o equilíbrio do meio ambiente no Planeta.

Assim como no PNAP, busca-se na PNGATI a implantação de sistemas de governança com a abertura de amplos espaços para a participação indígena, nos termos do art. 40, II, eixo 2, do Decreto n. 7.747//2.

No inciso III, eixo 3, do art. $4^{\circ}$, a PNGATI proporciona oportunidades para a solução dos problemas de sobreposições abordadas no item 3, além de possibilitar a participação das comunidades indígenas nas decisões sobre criação de UC no entorno da TI (Terra Indígena) e de integrarem o conselho gestor dessas áreas, o que também é atribuído à Funai nos casos de índios isolados.

Nos eixos 5 do inciso V, e 6 do inciso VI, o já referido Decreto n. 7.747, visa a implementar uma economia verde indígena, regulamentando o uso sustentável de suas riquezas naturais, protegendo a propriedade intelectual e o patrimônio genético, aí incluídos os:

[...] conhecimentos, práticas, usos tradicionais, costumes, crenças e tradições associados à biodiversidade e ao patrimônio genético existente nas suas terras, de forma a preservar seu direito na repartição dos benefícios, na forma da legislação vigente. (BRASIL, 2013 , online).

Ademais, no eixo 7 do inciso VII, o mesmo Decreto n. 7.747 cuidou de incluir dentre as diretrizes do PNAP a formação e capacitação técnica e científica sobre gestão 
territorial e ambiental, bem como sobre a PNGATI e sua governança, assim como a educação ambiental e indigenista para as comunidades vizinhas de suas terras.

As bases legais de inclusão das comunidades indígenas na chamada economia verde foram alicerçadas; entretanto, "ainda há muito chão pela frente", como se diz no jargão popular, pois existem déficits normativos e de implementação que precisam ser supridos para proporcionarem mais segurança no inter-relacionamento dos povos indígenas com a sociedade ocidental e sua economia, e consequentemente darem sustentabilidade a essas novas tendências.

\section{ZONAS DE AMORTECIMENTO, CORREDORES ECOLÓGICOS E MOSAICOS}

A ideia de zonas de amortecimento no entorno de unidades de conservação não é nova no ambientalismo brasileiro, a Lei n. 5. 197, de 3 de janeiro de 1967, em seu art. 10, alínea "f", já estabelecia a distância de cinco quilômetros no entorno de "estabelecimentos oficiais e açudes do domínio público, nos quais a utilização, perseguição, destruição, caça ou apanha de espécimes da fauna silvestre são proibidas."

A partir de então, o conceito de zona de amortecimento evoluiu para a atual disposição da Lei n. 9.985, de 2000, do SNUC, que a define como a área instituída no entorno de uma unidade de conservação, com normas e restrições específicas de atividades antrópicas, com a finalidade de abrandar o impacto deletério sobre a unidade de conservação.

Segundo Antonia Pereira de Avila Vio, a admissibilidade de alguma atividade antrópica na zona de amortecimento lhe dá caráter de autossustentabilidade, devendo sua definição ter o necessário dinamismo para não emperrar o processo ordenado de desenvolvimento. (VIO, 200 I , p. 348).

A zona de amortecimento deve conter certas características necessárias de proteção ao entorno da unidade de conservação, seja em relação a mananciais de água ou até mesmo a atividades turísticas no entorno da unidade.

A implantação desses cinturões de proteção no entorno de áreas indígenas, todavia, não tem previsão legal, apesar de já se discutir sua necessidade em casos específicos como o da Terra Indígena Zo'é, no Pará, tendo em vista que o desmatamento em seu entorno estaria propiciando a disseminação da malária entre os índios daquela etnia, segundo noticiou o Instituto Socioambiental (ISA) em 2007.

No caso da Terra Indígena Zo'é, há em sua vizinhança a Floresta Estadual Trombetas, área de proteção ambiental que pode facilitar a solução do problema, pois bastaria a inclusão no seu plano de manejo de uma espécie de "zona de amortecimento de impacto", segundo propõe o Ministério Público Federal no Pará, buscando uma solução por meio da interpretação analógica dos arts. $2^{\circ}, X V I I I$, e 25 da Lei n. 9.985, bem como dos arts. $8^{\circ}$ e seguintes do Decreto n. 4.340, de 2002, que dispõe, dentre outros assuntos, sobre a instituição de mosaicos de unidades de conservação. 
Além disso, o Conselho Nacional do Meio Ambiente (CONAMA) editou em 2006 a Resolução n. 378, dispondo sobre a exploração de florestas no entorno de terras indígenas demarcadas, na qual estabelece uma faixa de $10 \mathrm{~km}$ da linha limítrofe onde a exploração "que envolva manejo ou supressão de florestas e formações sucessoras" dependerá de autorização precedida de informação georreferenciada à Funai, abrindose exceção apenas para a pequena propriedade rural ou posse familiar rural, nos termos do art. $1^{\circ}, \S 2^{\circ}$, inciso I, da Lei n. 4.77I, de 1965, (hoje art. $3^{\circ}, \mathrm{V}$, da Lei n. 12.65I, de 2012, Código Florestal).

Além das zonas de amortecimento, a referida Lei n. 9.985 cuidou de prever a interligação das unidades de conservação em todo o território nacional por meio de corredores ecológicos, que também não são estranhos à legislação brasileira, uma vez que o Código Florestal de 1965, nos seus art. 2ª alínea "a", e art. 30, já instituía a proteção integral das faixas marginais situadas ao longo dos rios e cursos d'água, o que permitiu a criação de verdadeira malha de proteção ambiental, haja vista as unidades de conservação estarem entrecortadas por cursos hídricos ou mananciais que vertem para omar.

A Lei n. 9.985, no inciso XIX, do art. $2^{\circ}$, define corredores ecológicos como áreas de ecossistemas naturais ou seminaturais, que têm a função de interligar unidades de conservação e possibilitar o fluxo de genes e o movimento da biota entre elas, de modo a facilitar a dispersão de espécies e a recolonização de áreas degradadas, e também a manutenção de espécies que necessitam, para sobreviver, de áreas maiores do que a unidade de conservação.

A interrupção do fluxo gênico, a extinção de uma ou mais espécies e os processos erosivos, segundo Antonia Vio, são problemas que determinam a necessidade de corredores ecológicos. Segundo ela, a interrupção do fluxo gênico se caracteriza pela fragmentação do ecossistema por fatores antrópicos que cindem áreas ecologicamente propícias, interrompem o fluxo gênico, assim como a existência de área degradada (barreira ecológica) que separa duas áreas onde a espécie se mantém, desfavorecendo o ciclo evolutivo e o fluxo gênico entre as populações de ambas as áreas. De igual forma, "a concorrência pelo mesmo nicho nas áreas fragmentadas que não tenham conexão entre si pode provocar a extinção de uma ou mais espécies."(VIO, 200 I , p. 355).

Os corredores ecológicos constituídos nas margens dos cursos hídricos, no regime do Código Florestal, coincidem com Áreas de Preservação Permanente (APP), tão importantes para o sistema de áreas protegidas quanto às unidades de conservação. $E$ não poderia ser outra a concepção de corredor ecológico, tendo em vista que áreas degradadas no seu curso dificultariam ou mesmo impediriam o fluxo gênico.

As APPs são "[...] áreas sem definição geográfica e ocorrem em todo o território nacional, sendo que os corredores ecológicos naturalmente recaem sobre elas", acentua Antonia Vio (200 I , p. 356), situação que favorece a integridade do corredor ecológico. 
O regime jurídico dos Corredores Ecológicos ganhou funcionalidade com a edição das Resoluções n. 10, de 1993, e 9, de 1996, que estabeleceram suas características e amplitude com mais clareza, permitindo maior densificação da matéria no âmbito da Lei n. 9.985, do SNUC, malgrado as faixas de proteção de cursos d'água terem sofrido escalonamento não muito favorável ao fluxo gênico no âmbito da já referida Lei n. 12.65। (novo Código Florestal Brasileiro), que reduziu para dez metros as faixas de proteção nos cursos hídricos de até trinta metros de largura, escalonando-as, a partir daí, conforme arts. $4^{\circ}$ e seguintes, sendo que a proteção no Código Florestal revogado inciava-se com uma faixa de trinta metros para os cursos hídricos até dez metros de largura, e assim por diante, numa gradação mais generosa para com o meio ambiente.

Além das Zonas de Amortecimento e dos Corredores Ecológicos, complementam a unicidade do sistema os Mosaicos, que se afiguram possíveis, segundo o art. 26 da Lei do SNUC, na hipótese de "existir um conjunto de unidades de conservação de categorias diferentes ou não, próximas, justapostas ou sobrepostas, e outras áreas protegidas públicas ou privadas", cuja gestão deverá ser integrada e participativa, de modo a "compatibilizar a biodiversidade com a presença da sociodiversidade e o desenvolvimento sustentável no contexto regional."

O Decreto n. 4.340, de 2002, por sua vez, estabelece nos seus arts. $8^{\circ}$ e seguintes que o Mosaico depende de reconhecimento do Ministério do Meio Ambiente, a pedido dos órgãos gestores das UCs (art. $8^{\circ}$ ) e da instituição de um conselho consultivo, responsável pela gestão integrada das UCs, presidido por um dos seus chefes (art. $9^{\circ}$ ), com funcionamento e competência, que vai da disciplina do uso das fronteiras entre as unidades, acesso, fiscalização, monitoramento e avaliação dos planos de manejo, pesquisa científica, alocação de recursos, inter-relacionamento com a população residente, até a manifestação sobre propostas para solução de sobreposições (art. 10).

As hipóteses legais de solução para os conflitos socioambientais no Brasil, principalmente na Amazônia, como se observa, são diversas, o que falta é a efetivação da vontade do legislador por meio de políticas públicas adequadas para que o Estado socioambiental ganhe amplitude.

\section{GOVERNANÇASOCIOAMBIENTAL DE MOSAICOS}

A ideia de instituição de Mosaicos, a princípio, visava a atender situações pontuais na Mata Atlântica, onde as pequenas Unidades de Conservação, muitas vezes de categorias diferenciadas, públicas ou privadas, próximas ou não, sobrepostas ou não, eram geridas isoladamente, com baixos resultados, deixando de abranger adequadamente os processos que geram e mantêm a biodiversidade, cujos fluxos biótico e gênico transcendem os limites da Unidade de Conservação.

Apesar de terem sido incluídos no Sistema Nacional de Unidades de Conservação (SNUC), em seus arts. 26 e seguintes, e regulamentados por meio do Decreto $\mathrm{n}$. 4.340, de 2002, os Mosaicos somente ganharam ênfase socioambiental alguns anos 
depois, no Plano Estratégico Nacional de Áreas Protegidas (PNAP), o qual abriu a perspectiva de integração entre terras indígenas, quilombolas e unidades de conservação, e prestigiou seus conhecimentos tradicionais, prevendo a inclusão desses povos na gestão de unidades de conservação.

O mesmo Decreto do PNAP também incluiu entre seus princípios e diretrizes o uso sustentável dessas áreas e a harmonização das políticas públicas pertinentes, nos três níveis de governo, inclusive no que se refere ao ordenamento do território.

Os princípios e diretrizes do PNAP encontraram ressonância na Política Nacional de Gestão Territorial e Ambiental de Terras Indígenas (PNGATI), instituída pelo Decreto n. 7.747, de 20 I 2, no qual é reconhecido o valor ambiental das terras indígenas, o direito de os índios perceberem vantagens com a prestação de serviços ambientais e a possibilidade de participarem dos conselhos gestores de unidades de conservação, assim como no planejamento da ordenação do território.

O Supremo Tribunal Federal tem dado concreção a essa vertente socioambiental de integração entre UCs e Tls, reconhecendo que os índios vivem equilibradamente no ambiente natural e podem auxiliar na preservação ambiental de outras áreas protegidas, além de sinalizar positivamente para a implantação de corredores ecológicos, integrando diversas áreas protegidas em uma macrorregião compartilhada, o que efetivamente pode significar a salvação de grande parte da Amazônia Brasileira.

$\bigcirc$ Parque Nacional do Xingu, ou Parque Indígena do Xingu (PIX), a maior terra indígena do Planeta, é um exemplo de projeto indigenista bem-sucedido, com importantes repercussões ambientais, demonstrando na prática que é possível conservar o ambiente com a ajuda dos índios, seus naturais protetores.

Essa bem-sucedida experiência do PIX em relação à conservação ambiental, com programas desenvolvidos pelos próprios índios do Xingu, clamam a favor de uma solução similar para o Sistema Nacional de Unidades de Conservação em que as populações tradicionais e indígenas possam auxiliar na fiscalização, gestão e manejo das demais unidades de conservação, principalmente em razão dos conhecimentos tradicionais que possuem, mas apesar disso, dos doze Mosaicos instituídos no Brasil, cinco estão na Amazônia e somente no Mosaico Oeste do Amapá e Norte do Pará estão incluídas Terras Indígenas (TI Wajãpi, TI Parque do Tumucumaque e TI Paru D'Este).

Além disso, é preciso implementar, no âmbito dessa governança, as Diretrizes do art. $3^{\circ}$, X e XII, do PNGATI, o Princípio I I I , XIX, e Diretriz I.2, XI, e 7, I e II, do PNAP, e do art. 4 I do Código Florestal, com vistas a instituir recompensa pela prestação de serviços ambientais aos indígenas e comunidades tradicionais, providência que trará sensíveis melhorias ao setor, o qual sofre com a falta de funcionários para as diversas funções que o sistema exige, inclusive no que se refere à fiscalização.

Alexandra Aragão tem defendido a busca por uma valoração dos serviços ecossistêmicos, e identifica, nesse aspecto, um ganho de forma do dever de valor nos arcabouços jurídicos internacional, europeu e português. (2012, p. 13-29). 
Apesar de não ser a única forma de compensação, o incentivo financeiro para execução de tarefas de preservação ambiental é fator de inclusão social.

O novo Código Florestal incluiu, dentre os serviços ambientais, "[...] a conservação da biodiversidade" e "a valorização cultural e do conhecimento tradicional ecossistêmico [... ]", nos termos do art. 4I ; mas a matéria ainda necessita de melhor regulamentação no âmbito do direito indigenista brasileiro.

Apesar da demora na regulamentação, o incentivo ao pagamento de serviços ambientais vem ocorrendo paralelamente em diversos segmentos da economia brasileira, a exemplo do art. 36 da Lei do SNUC, a qual trouxe para o sistema jurídico ambiental uma nova forma de compensação financeira para captar recursos destinados à manutenção de unidades de conservação do grupo de proteção integral.

Outras práticas governamentais já se alinham a essas novas tendências, como o Bolsa Verde do Governo Federal, um subprograma do Brasil Sem Miséria, voltado para as populações rurais vulneráveis (ALTMANN, 2014, p. I0-II), e a Portaria Funai n. I.682, de 8 de dezembro de 20 I I, a qual "estabelece diretrizes e critérios a serem observados na concepção e execução das ações de proteção territorial e etnoambiental em terras indígenas", possibilitando em seus arts. $4^{\circ}$ e seguintes auxiliar financeiramente os indígenas que participarem das "ações de proteção territorial e etnoambiental nas terras indígenas e para estabelecer prioridades de atividades a serem desenvolvidas com vistas a promover a integridade efetiva das terras indígenas e suas riquezas naturais [...]", inclusive na proteção de povos isolados.

A ideia de remuneração do índio para tarefas dessa natureza, segue a diretriz do Decreto n. 4.519, de 2002, o qual dispõe sobre serviços voluntários em unidades de conservação, e, pode abranger também as hipóteses de vigilância, manejo e gestão de Mosaicos, conforme foi dito alhures.

Essa vertente tem sido a diretriz da política ambiental de alguns Estados da Amazônia, a exemplo do Amazonas. Após receber o programa Bolsa Verde, o Governo Federal, instituiu, por meio da Lei Complementar 53, de 2007, o Sistema Estadual de Conservação do Amazonas, assim como a Política Estadual sobre Mudanças Climáticas, Conservação Ambiental e Desenvolvimento Sustentável do Amazonas, por meio da Lei n. 3. I35, modificada pela Lei n. 3. I 84, ambas de 2007, e o Bolsa Floresta do Estado do Amazonas, este por meio do Decreto n. 26.958, de 2007. (ALTMANN, 20 I4, p. I0II).

De igual modo, o Estado do Acre instituiu o Programa Estadual de Certificação de Unidades Produtivas Familiares do Estado do Acre, por meio da Lei n. 2.025, de 2008, cuja finalidade é:

[...] estabelecer um processo voluntário de certificação socioambiental nas pequenas propriedades familiares [...], o uso sustentável dos recursos naturais e a gestão adequada do território [...], a valorização dos serviços ambientais e do ativo ambiental florestal do Acre. (ALTMANN, 20 | 4, p. I 0- I I). 
Além disso, foi criado o Sistema Estadual de Incentivos a Serviços Ambientais pela Lei n. 2.308, de 2010, para fomentar e ampliar a oferta de:

(I) seqüestro, conservação, manutenção e aumento do estoque e a diminuição do fluxo de carbono, (II) conservação da beleza cênica natural, (III) conservação da sociobiodiversidade, (IV) conservação das águas e dos serviços hídricos, (V) regulação do clima, (VII) conservação e o melhoramento do solo.

A manutenção, pelos indígenas, das florestas existentes em suas terras e nas Unidades de Conservação vizinhas, de modo a manter baixo nível entrópico, constituise numa prestação de serviços de valor considerável para a sociedade em geral, mas, ao lado disso, é preciso avançar na regulamentação federal, inclusive numa reforma tributária que institua os chamados impostos verdes e incentivos financeiros ao pagamento por serviços ambientais, com mecanismos de maior inclusão social, principalmente das comunidades tradicionais e indígenas, cujo modo de vida integrado ao meio ambiente encontra- se ameaçado pelo desenvolvimento econômico.

Com isso, abre-se a perspectiva de reduzir o déficit orçamentário do sistema de manutenção de Unidades de Conservação, que já alcança o patamar de um bilhão de reais. (ARAÚJO, 20 I 2, p. I22- 1 23).

\section{O ORDENAMENTO DO TERRITÓRIOSOB OPRISMASOCIOAMBIENTAL}

Antonio José de Mattos Neto argumenta que a Constituição do Estado do Pará, de 5 de outubro de 1989, "[...] emprestou ao tema meio ambiente sentido mais próximo do aspecto econômico, como que denotando que a atividade econômica deve ser conjugada com o meio ambiente [...]", ao tempo em que noticia a regulamentação da ordenação do território paraense por meio de zoneamento ecológico-econômico previsto na Lei Estadual de Política do Meio Ambiente (Lei n. 5.887, de 9 de maio de 1995). Mattos Neto salienta que "[...] é fundamental para o ordenamento territorial, em razão de a Amazônia não ser um espaço homogêneo, constituindo verdadeiro mosaico agroambiental [.....". (2010, p. 96-97).

O zoneamento ecológico-econômico, segundo Mattos Neto:

[...] tem função de ser um parâmetro balizador do avanço, de forma racional e ordenada, da ocupação econômica regional, obedecendo-se as vocações naturais do espaço regional. Não se descurando, todavia, da importância estratégica que o conhecimento tecnológico atual assume da condição de adequá-lo ou ampliá-lo. (20 I0, p. 96-97).

Ao instituir sua política de reforma agrária pela Lei n. 8.629, de 25 de fevereiro de 1993, em atenção ao disposto no art. 225 da Constituição, a União estabeleceu como primordial o princípio da função social da propriedade, utilizado em diversos dispositivos 
do texto, principalmente no art. $9^{\circ}$, dentro de um critério de gradação do que considera exploração racional e vocacional da terra, conjugado com a preservação do ambiente.

Ao abranger as comunidades vizinhas, o legislador ampliou a noção de equilíbrio ambiental para o exterior da propriedade rural, de modo a não permitir que a utilização dos seus recursos naturais provoque danos ou ameaças à vizinhança, princípio que deve nortear também as políticas públicas de desapropriação e assentamento de colonos, principalmente se colocar em risco unidades de conservação e terras indígenas, daí ser preponderante um zoneamento econômico-ambiental nos moldes propostos pelo legislador paraense, com regras mais claras sobre os limites definidos das zonas de amortecimento e corredores ecológicos no entorno de terras indígenas e unidades de conservação, e regras para o estabelecimento e exploração de propriedades rurais na vizinhança. Destaca-se, também, a experiência do Estado de São Paulo em relação ao zoneamento sucroalcooleiro.

Conquanto o território brasileiro esteja dividido em Estados Federados com a autonomia que lhes garante a Constituição, compete constitucionalmente à União, nos termos do artigo $2 \mathrm{I}$, inciso IX, "[...] elaborar e executar planos nacionais e regionais de ordenação do território e de desenvolvimento econômico e social."

A busca por uma melhor ordenação do território brasileiro, em cooperação com Estados e Municípios vem sendo desenvolvida após a Constituiçãa de 1988. Mas somente em 2003, pela Lei n. 10.683, estabeleceram-se as atribuições dos Ministérios da Integração Nacional e da Defesa, propiciando que em 2004 o Ministério da Integração Nacional apresentasse seu projeto de Política Nacional de Ordenamento Territorial (PNOT), cujas diretrizes também abrangem a proteção do ambiente e de comunidades indígenas e tradicionais. No entanto, o documento não tem passado de uma carta de intenções, pois não se tem notícias de ações que lhe deem efetividade.

O próprio Código Florestal, de 2012, traz a possibilidade de amplo zoneamento ecológico-econômico a ser realizado em cooperação pela União e pelos entes federados, conforme se depreende do art. 13, no qual o prazo de cinco anos é fixado para os estados, que ainda não possuem esse zoneamento, providenciá-lo.

zoneamento ecológico-econômico é fator primordial para o crescimento planejado, não só da agricultura, carro-chefe da economia brasileira, mas de toda a economia, com "cartas na mesa".

A situação de desordem só favorece as práticas ilegais e clandestinas, que acabam empobrecendo os próprios Estados, Municípios e principalmente a União, uma vez que o alvo preferencial dos depredadores são terras indígenas e outras áreas protegidas.

\section{CONCLUSÃO}

Sistema Nacional de Unidades de Conservação (SNUC) contempla a possibilidade de composição de Mosaicos entre as Unidades de Conservação, sejam de máxima proteção ou de uso sustentável; contudo, não incluiu inicialmente no sistema as 
Terras Indígenas, lacuna suprida posteriormente pelo Plano Estratégico Nacional de Áreas Protegidas (PNAP), o qual estabeleceu um elo entre o SNUC e o Estatuto do Índio, situação consolidada na Política Nacional de Gestão Ambiental de Terras Indígenas (PNGATI).

O reconhecimento infraconstitucional do valor ambiental das terras indígenas e das populações tradicionais, garantido pela Constituição de 1988, possibilita a inclusão dessas áreas no sistema nacional e na composição de Mosaicos, e a inclusão dessas comunidades na gestão de áreas protegidas, constituindo-se em fator de concreção do princípio democrático e da proteção do ambiente, além de inclusão social.

A promoção da reordenação do território pela União, Estados e Municípios, em regime de cooperação, e dentro de critérios econômico-ecológicos, e a instituição de Mosaicos de áreas protegidas, compostas por Unidades de Conservação (federais, estaduais e municipais), Terras Indígenas, terras de populações tradicionais, ladeadas por Zonas de Amortecimento e interligadas com outros Mosaicos ou áreas protegidas por Corredores Ecológicos, abre a perspectiva de melhor gestão do Sistema Nacional de Unidades de Conservação, uma vez que possibilita maximizar recursos, diminuir a entropia e propiciar melhor fluxo gênico.

A compensação financeira por serviços ambientais prestados por indígenas e populações tradicionais na salvaguarda de suas terras e de outras áreas protegidas é medida de relevante valor socioambiental que pode maximizar a proteção do ambiente, reduzir gastos e promover a democracia.

\section{REFERÊNCIAS}

ACRE. Lei n. 2.025, de 20 de out. de 2008. Cria o Programa Estadual de Certificação de Unidades Produtivas Familiares do Estado do Acre. Disponível em: <http://www2.camara.leg.br/atividade-legislativa/comissoes/comissoespermanentes/cmads/seminarios-e-outros-eventos/eventos-2014/seminarios/20 I 404-24\%20-\%20PSA/apresentacoes/marcia-stanton/view > . Acesso em: 3 jun. 2014.

Lei n. 2.308, de 22 de outubro de 20 I0. Cria o Sistema Estadual de Incentivos a Serviços Ambientais- SISA, o Programa de Incentivos por Serviços Ambientais - ISA Carbono e demais Programas de Serviços Ambientais e Produtos Ecossistêmicos do Estado do Acre e dá outras providências. Disponível em: <http://www.imc.ac.gov.br/wps/wcm/connect/cbal I f804e8d380 I b88cfb7a8 I aad2ff /Lei2308_l.pdf?MOD=AJPERES > . Acesso em: 3 jun.20 I 4.

ALTMANN, Alexandre. Pagamento por serviços ambientais. In: GOMES, Carla Amado (Coord.). Compensação ecológica, serviços ambientais e proteção da biodiversidade. Lisboa: ICJP, 20 I4. p. 7-3I. 
AMAZONAS. Decreto n. 26.958, de 4 de setembro de 2007. Institui o Programa bolsa Floresta do Governo do Estado do Amazonas, na forma que especifica, e da outras providências. Disponível e m : <http://www.ipaam.br/legislacao/ESTADUAL/dec.est\%20n.\%C2\%BA\%2026.958\% 20de\%2004.09.07\%20(\%20institui\%20o\%20programa\%20bolsa\%20floresta).doc $>$. Acesso em: 3 jun. 2014.

. Lei Complementar n. 53, de 5 de junho de 2007. Regulamenta o Inciso V do artigo 230 e o § I. ' do artigo 23 I da Constituição Estadual, institui o Sistema Estadual De Unidades De Conservação - SEUC, dispondo sobre infrações e penalidades e estabelecendo outras providências. Disponível em: <http://legislador.aleam.gov.br/LegisladorWEB/LegisladorWEB.ASP?WCI=LeiTexto\& $I D=20 \mid$ \&inEspecieLei $=2 \& n r L e i=53 \&$ aaLe $i=2007 \& d s V$ erbete $=>$. Acesso em: 3 jun. 2014.

. Lei n. 3.135, de 5 de junho de 2007, alterada pela Lei 3.184, de 13 de

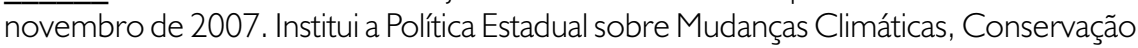
Ambiental e Desenvolvimento Sustentável do Amazonas, e estabelece outras providências. Disponível em: <http://ebookbrowsee.net/lei-complementar-n-532007-amazonas-pdf-d I | 4492445>. Acesso em: 3 jun. 20 I 4.

ARAGÃO, Maria Alexandra. A natureza não tem preço, mas devia. In: SOUSA, Marcelo Rebelo de; QUADROS, Fausto de; OTERO, Paulo et al. (Coords.). Estudos de Homenagem ao Prof. Doutor Jorge Miranda. Lisboa: FDUL; Coimbra, 20 I2, p. II4I.v. 4.

ARAÚJO, Marcos Antônio Reis. Unidades de conservação: a importância e história no mundo. In: NEXUCS (Org.). Unidades de conservação no Brasil: o caminho da gestão para resultados. São Carlos: RIMA, 20 I2. p. 25-50.

BATALLA, Guilhermo Bonfil. México profundo. Una civilización negada. Edición original de la Secretaria de Educación Pública/Centro de Investigaciones y Estudios Superiores em Antropologia Social - CIESAS. México: Grijalbo, 1990.

BELTRÃO, Antonio F. G. Unidades de uso sustentável e de proteção integral: diferenças, semelhanças e adequação na escolha. In: AHMED, Flávio; COUTINHO, Ronaldo (Coords.). Tutela Jurídica das Áreas Protegidas. Rio de Janeiro: Lumen Juris, 201 I . p. $1-12$. 
BRASIL. Decreto n. 4.340, de 22 de agosto de 2002. Regulamenta artigos da Lei n. 9.985, de 18 de julho de 2000, que dispõe sobre o Sistema Nacional de Unidades de Conservação da Natureza-SNUC, e dá outras providências. Disponível em: <http://www.planalto.gov.br/ccivil_03/decreto/2002/d4340.htm>. Acesso em: 18 nov. 2013.

Decreto n. 4.519, de 13 de dezembro de 2002. Dispõe sobre o serviço voluntário em unidades de conservação federais, e dá outras providências. Disponível em: <http://www.planalto.gov.br/ccivil_03/decreto/2002/D45 I 9.htm>. Acesso em: 3 de jun. 2014.

Decreto n. 5.758, de 13 de abril de 2006. Institui o Plano Estratégico Nacional de Áreas Protegidas-PNAP, seus princípios, diretrizes, objetivos e estratégias, e dá outras providências. Disponível em: <http://www.planalto.gov.br/ccivil_03/_Ato20042006/2006/Decreto/D5758.htm>. Acesso em: 2 I mar. 2014.

Decreto n. 7.747, de 05 de junho de 2012. Institui a Política Nacional de Gestão Territorial e Ambiental de Terras Indígenas - PNGATI, e dá outras providências. Disponível em: <http://www.planalto.gov.br/ccivil_03/_ato201I2014/2012/decreto/d7747.htm >. Acesso em: I 8 nov. 2013.

. Fundação Nacional do Índio. Portaria n. I.682, de 8 de dezembro de 201 I . Diário Oficial da União de 13 de dezembro de 20ll. Disponível em: <http://pesquisa.in.gov.br/imprensa/core/consulta.action>. Acesso em: 20 mar. 20 I 4.

Lei n. 5.197, de 3 de janeiro de 1967. Dispõe sobre a proteção à fauna e dá outras providências. Disponível e m: <http://www.planalto.gov.br/ccivil_03/leis/15197.htm>. Acesso em: 3 jun. 2014.

. Lei n. 5.37I, de 5 de dezembro de 1967. Autoriza a instituição da "Fundação Nacional do Índio" e dá outras providências. Disponível em: <http://www.planalto.gov.br/ccivil_03/Leis/I950- 1969/L537l.htm>. Acesso em: 3 jun. 2014.

Lei n. 8.629, de 25 de fevereiro de 1993. Dispõe sobre a regulamentação dos dispositivos constitucionais relativos à reforma agrária, previstos no Capítulo III, Título VII, da Constituição Federal. Disponível em: <http://www.planalto.gov.br/ccivil_03/LEIS/L8629.htm>. Acesso em: I 6 mar. 2014. 
. Lei n. 9.985, de I 8 de julho de 2000. Regulamenta o art. 225, § I o, incisos I, II,

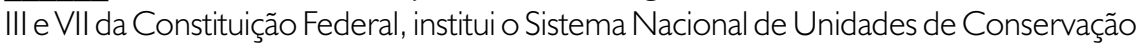
da Natureza e dá outras providências. Disponível em: <http://www.planalto.gov.br/ccivil_03/leis/19985.htm>. Acesso em: I 8 nov. 2013.

. Lei n. 10.683, de 28 de maio de 2003. Dispõe sobre a organização da Presidência da República e dos Ministérios, e dá outras providências. Disponível em: <http://www.planalto.gov.br/ccivil_03/leis/2003/10.683.htm>. Acesso em: 16 mar. 2014 .

Lei n. 12.65 I, de 25 de maio de 20 I2. Dispõe sobre a proteção da vegetação nativa; altera as Leis nos 6.938, de 3 I de agosto de 1981 , 9.393, de 19 de dezembro de 1996, e II.428, de 22 de dezembro de 2006; revoga as Leis nos 4.77I, de 15 de setembro de 1965, e 7.754, de 14 de abril de 1989, e a Medida Provisória n. 2. I66-67, de 24 de agosto de 200l; e dá outras providências. Disponível em: <http://www.planalto.gov.br/ccivil_03/_ato20 I I- 20|4/20I2/lei/l I265 I.htm>. Acesso em: 25 maio 2014.

- Ministério da Integração Nacional. Política Nacional de Ordenamento Territorial. Disponível e m : <http://www.mi.gov.br/c/document_library/get_file?uuid=3fc3 Id I6-e5f7-46fbb8cc-0fb2ae |76|7| \&groupld=249| 5>. Acesso em: 17 mar. 2014.

Ministério do Meio Ambiente. Resolução 378/CONAMA. Define os empreendimentos potencialmente causadores de impacto ambiental nacional ou regional para fins do disposto no inciso $1 \mathrm{II}, \S 1^{\circ}$, art. 19 da Lei n. 4.77I, de 15 de setembro de 1965, e dá outras providências. Disponível em: <http://www.mma.gov.br/port/conama/res/res06/res37806.pdf>. Acesso em: 6 jun. 2014.

Supremo Tribunal Federal. Petição n. 3.388. Rel. Min. Carlos Ayres Brito. Revista Trimestral de Jurisprudência, Brasília, v. 212, p. 49-37। , abr./jun. 2010.

DIEGUES, Antonio Carlos. O mito moderno da natureza intocada. 3. ed. São Paulo: Hucitec, 2001 .

INSTITUTO SOCIOAMBIENTAL - ISA. MPF quer que plano de manejo de floresta ajude a evitar malária entre os Zo'é. Disponível em: <http://siteantigo.socioambiental.org/nsa/detalhe?id=2394 > . Acesso em: 3 jun. 2014. 
MATTOS NETO, Antonio José de. Estado de direito agroambiental brasileiro. São Paulo: Saraiva, 2010.

ORGANIZAÇÃO DAS NAÇÕES UNIDAS - ONU. Resoluções. Resolução 6I/295. Declaração das Nações Unidas sobre Direitos dos Povos Indígenas. Disponível em: <http://www.un.org/Depts/dhl/resguide/r6 I sp.htm>. Acesso em: I mar. 2014.

. Resolução 66/288. O futuro que queremos. Disponível em: <http://www.un.org/ga/search/view_doc.asp?symbol=A/RES/66/288>. Acesso em: I mar. 2014

. Convenção sobre Diversidade Biológica - CDB. Disponível em: <http://www.onu.org.br/rio20/img/2012/0I/cdb_ptbr.pdf>. Acesso em: I mar. 2014 .

Conferência das Partes - COP7. Disponível em:

$\overline{<w w w . c b d . i n t / d e c i s i o n s / ? m=c o p-07>. ~ A c e s s o ~ e m: ~} 3$ jun. 2014.

Conferência das Partes - COP8. Disponível em:

<http://www.cbd.int/kb/Results?FreeText=COP8>. Acesso em: 3 jun. 2014.

PARÁ. Lei n. 5.887, de 09 de maio de 1995. Dispõe sobre a Política Estadual do Meio Ambiente e dá outras providências. Disponível em: <http://www.ideflor.pa.gov.br/file/LEI\%20N\%205.887,\%20de\%2009\%20de\%20 Maio\%20de\%201995.pdf>. Acesso em: 3 jun. 2014.

SANTOS, Boaventura de Souza. Cuando los excluidos tienen Derecho: justicia indígena, plurinacionalidad e interculturalidad. In: .; RODRÍGUEZ, José Luis Exeni (Ed.). Justicia indígena, plurinacionalidad e interculturalidad en Bolivia. Quito: Fundación Rosa de Luxemburgo, 20 12. p. I I-48.

SANTILLI, Juliana. Socioambientalismo e novos direitos: proteção jurídica à diversidade. São Paulo: Fundação Petrópolis, 2005.

SÃO PAULO. Secretaria do Meio Ambiente. Zoneamento agroambiental para o setor s u c ro a l coole i ro. <http://www.ambiente.sp.gov.br/cpla/zoneamento/zoneamento-ecologicoeconomico/>. Acesso em: 16 mar. 2014. 
REORDENAÇÃO DO TERRITÓRIO E GOVERNANÇA SOCIOAMBIENTAL: OS MOSAICOS DE ÁREAS PROTEGIDAS NO BIOMA AMAZÔNIA

SEN, Amartya. A ideia de justiça. Trad. de Denise Bottmann e Ricardo Doninelli Mendes. São Paulo: Companhia das Letras, 201 I.

SOARES, Guido Fernando da Silva. Direito internacional do meio ambiente: emergência, obrigações e responsabilidades. São Paulo: Atlas, 2001 .

VERÍSSIMO, Adalberto (Org.). Áreas protegidas na Amazônia Brasileira: avanços e desafios. Belém: Imazon; São Paulo: Instituto Socioambietal, 201 l.

VILLAS BOAS, Marco Anthony Steveson. Proteção ambiental das reservas indígenas. In: Revista do Instituto do Direito Brasileiro da Faculdade de Direito da Universidade de Lisboa, Lisboa, 2013al, n. 4, p. 3.369-3444 e 2013a2, n. 5, p. 4556-4632. Disponível e m: < t t p : / / w w w. id b fdul.com/uploaded/files/20I3_04_03369_03444.pdf>. Acesso em: 3 jun. 2014.

. Repercussões ambientais do indigenato. Revista CEDOUA, Coimbra, ano I6,

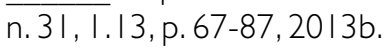

VIO, Antonia Pereira de Avila. Zona de Amortecimento e Corredores Ecológicos. In: BENIAMIN, Antonio Herman (Coord.). Direito ambiental das áreas protegidas: 0 regime jurídico das unidades de conservação. Rio de Janeiro: Forense, 200 I. p. 348360.

Recebido em: 27/10/2016 Aprovado em: 05/11/2016 
